\title{
Critical Success Factors of Public Private Partnership in Hydropower Sector of Nepal
}

\author{
Chinta Mani Gautam'
}

\begin{abstract}
This paper aims to identify the Critical Success Factors (CSFs) of Public Private Partnership (PPP) in hydropower secter of Nepal. The study was based on a survey of 141 experts and practitioners involved in private and public hydropower projects. The study revealed that project technical feasibility, favorable legal framework, good governance, transparent procurement process and macro-economic stability were identified as most CSFs of PPPs. The comparative analysis of rank, found that among the $21 \mathrm{CSF}$, four factors: macro-economic condition, employment opportunities, government's technical support and government's managerial support were considered equally important CSFs by the public and private sector respondents. It is concluded that for the success of PPPs in hydropower sector, the concerned authorities should use private sector more efficiently, specially for the technical support and government for devising favorable legal framework for the PPP projects. This study offers some insights on CSFs for policy makers concerning the successful implementation of PPPs in hydropower sector.
\end{abstract}

Key Words: Public private partnership, Hydropower sector, Critical success factors.

\section{INTRODUCTION}

Public Private Partnership (PPP) model was originated during 1930s due to shortcomings of the public institutions in the service delivery and the consequences of inefficient fiscal policies. The emergence of PPPs concept is explicitly witnessed from the backdrop of the overall failure in national economy resulting from mass unemployment and deflation due to market monopolies from either side (Nsasira, 2013). The PPPs have many objectives including developing infrastructure, boosting local economy, reducing costs, enhancing good governance, increasing construction

Mr. Gautam is Lecturer at Public Youth Campus, Tribhuvan University.

Email: cmgakshay@gmail.com 
and operation efficiencies, and improving service quality by using private sector's capital, knowledge, and expertise (Yuan, 2009). The PPPs transfer risk from the public to the private sector as private sector is better capable to manage risk. The PPPs is not only characterized by the sharing of investment, risk, responsibility and reward between the partners (Akintoye, Beck, \& Hardcastle, 2003), but also achieving efficiency and effectiveness in operation of an entity (Municipal Ministry of Municipal Affairs, 1999, cited by Bojovic, 2006) involving the citizens in decision making process.

In many areas of public sector responsibility, inclusiveness is a better option to deliver services effectively. This is often encouraged because of the dynamics of competition, or because it brings advanced technical or risk management capacity (Grimsey, 2002). By bringing private capital into state enterprises, countries could gain access to technology and skill transfer, as well as to capital needed for expansion and organizational renewal.

The PPPs can involve in design, construction, financing, operation and maintenance of public infrastructure and facilities, or the operation of services, to meet public needs. They are often privately financed and operated on the basis of revenues received for the delivery of the facility and/or service (Alinaitwe \& Ayesiga, 2013). One key to this is providing private sector more favorable long term financing options than may be available to a government entity and to secure the financing in a much quicker time frame (Jefferies, 2006).

\section{PPPs and Hydropower Sector of Nepal}

A few hydropower projects including Khimti and Bhotekoshi have been developed using FDI so far in Nepal. In the last few years, the government came up with a series of hydropower-friendly policies to attract domestic investment in the energy sector through tax rebates, availability of loans at concession, attractive power purchase agreement (PPA) rate, and waived value added tax on construction materials (Paudel, 2013). Though the concept of PPPs in Nepal has become decades old, it is still not popular in all sector except hydropower. Nepal has achieved success in developing hydropower project under PPPs model. Initial observation of PPPs in hydropower sector of Nepal has shown positive vibe.

The PPPs in Nepal has channelized scattered capital in the form of remittances or other means, putting them to productive use. Further, the risk has equitably shared by all parties including locals; there is a greater transference of responsibility which enhances efficiency and guarantees higher returns. Besides, local participation in the project in the form of investment and employment, created multiplier effects in the local economy, with higher productivity and consumption (Paudel, 2013).

Of the world's capacity, Nepal has the potential of producing more than 299 TWh/year $(83000 \mathrm{MW})$ of electricity, which is almost $3 \%$ of the whole world's capacity. Almost $96 \%$ of the electricity produced today comes from hydropower plants (Adhikari, 2011). The Electricity Act of 1992 paved the way for participation of the private sector 
in electricity generation. The privatization of Butwal Power Company in January 2003 further augmented the private sector's role in hydro-power development and established Himal Hydro and General Construction Company and Nepal Hydro and Electric Ltd as Nepal's indigenous hydropower companies with international reputation. However, the role and capacity of the private sector in Nepal's energy development so far has, at best, only been supplementary (Paudel, 2010).

The Chilime Hydropower Company Limited (CHCL), which has been developed under PPP model, is a good example of how local participation and ownership can facilitate timely completion of the projects (Paudel, 2010). Giving ownership to the people living in the project affected area in the project not only put legal claims at rest, it also facilitated acquisition and compensation issues. After the success of $\mathrm{CHCL}$, most of the hydropower projects of Nepal have been initiated in PPPs model.

The unique characteristics of PPPs to a particular country require a study on CSFs specifically for PPPs in Nepal. Hence, this study fills the gap by investigating the CSFs for implementation of PPPs in Nepal. The growing energy crisis, and development of PPPs policy in hydropower have motivated the author to conduct this research to find out the importance of CSFs for the successful implementation of PPPs in hydropower sector. Therefore, the main objective of the study is to identify the critical success factors of PPPs in hydropower sector of Nepal and to compare the perception of public and private sectors on CSFs of PPPs in hydropower projects.

\section{REVIEW OF LITERATURES}

Despite the unique characteristics of individual PPPs, prior literature has examined the CSFs for PPPs in general. CSFs have been identified by many researchers to improve the success rate of PPP projects around the world. Jefferies, Gameson and Rowlinson (2002) identified and examined 15 success factors relevant to the project and the most significant CSFs include: 'compatibility/complimentary skills among the key parties', 'technical innovation in overcoming project complexity' and 'efficient approval processes'. Other important success factors include 'environmental impact', 'developed legal/economic framework', 'political stability', 'selecting the right project', 'existing strategic alliances', 'good resource management', 'trust', 'community support', 'feasibility study', 'transfer of technology', 'financial capability', and 'consortium structure'. Likewise, Jefferies (2006) identified the same CSFs as reported by Jefferies, Gameson and Rowlinson (2002), and included new success factors: 'negotiation', 'client brief/outcome', 'bid feature', 'business diversification', 'business viability', 'competition', 'credit rating investor', 'teamwork', 'existing infrastructure', 'delivery of asset', 'investment growth', and 'project identification'. The findings revealed that the most important success factors for the Super Dome project were: 'the issue of bidding, which is successfully, managed by the government', 'the project agreement, which is a very streamlined approval 'and, 'the negotiation process'.

Jamali (2004) investigated the CSFs for PPPs in the telecommunication industry 
in Lebanon. The findings are: 'trust', 'openness' and 'fairness' are most CSFs of PPPs. Zhao et. al (2010) examined the success of two PPPs power projects - thermal power and wind power and identified 31 success factors for the power projects. The study revealed common CSFs for the two projects, which include: 'the necessity for the project', 'the expected debt paying ability of the project' and 'the financial capacity of the contractor'. In addition, there are CSFs that are unique to the individual projects. For the thermal power, 'level of project financing management of the project company' and 'level of business operation and qualification of the contractor' are the important CSFs while for the wind power, 'competency of personnel of the project company', 'financial capacity of the contractor', 'expected profitability of the project', and 'legal environment' are the CSFs.

Aziz and Kassim (2011) examined the CSFs of ten PPPs housing projects in Malaysia and identified 15 success factors for PPPs housing projects: 'action against errant developer', 'robust and clear agreement', 'reputable developer', 'constant communication', 'developer's profit sharing accountability', 'developer's social accountability', 'house buyer's demand', 'negotiation skills', 'adequate negotiation staff', 'realistic projection', 'competition', 'ample time to evaluate proposal', 'political influence', 'consistent monitoring', and 'compatibility between partners'. The results reveal that all 15 factors except 'political influence' contribute significantly to the success of a PPPs housing project.

Frilet (1997) studied 'social support factor' and identified it only critical success factor of PPPs. Li (2005) identified three most important factors: 'a strong and good private consortium', 'appropriate risk allocation' and 'available financial market'. Grant (1996) identified 'multi benefit objectives' and 'appropriate risk allocation and risk sharing factor' as CSFs of PPPs.

Zhang (2005) identified 47 CSFs of PPPs, which have been classified into five main aspects of CSFs: 'economic viability', 'appropriate risk allocation via reliable contractual arrangements', 'sound financial package', 'reliable concessionaire consortium with strong technical strength', and 'favorable investment environment'. Jacobson and Choi (2008) find that 'high degree of commitment' and 'shared vision between the client, architect, and contractor' are the most important factors for construction success. Qiao et al. (2001) identified 'stable macroeconomic environment', 'available financial market', 'appropriate risk allocation and risk sharing', 'project technical feasibility', 'political parties positive outlook towards the PPPs', 'good governance', and 'government involvement by providing guarantee' as CSFs of PPPs.

\section{Theoretical Framework}

In order to examine the CSFs influencing the PPPs in hydropower sector, six independent variables have been identified: Favorable economic condition, Project implementability, Effective procurement, Stable political environment, Social environment, and Government support. 


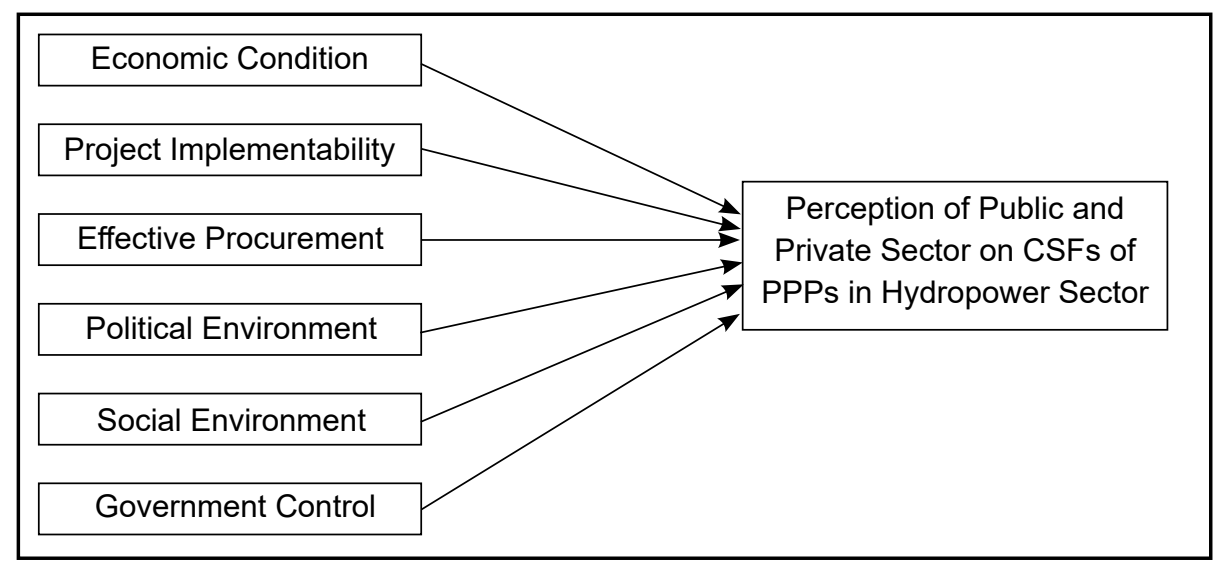

Figure 1: Theoretical Framework

\section{RESEARCH METHODS}

The descriptive research design with opinion survey has been used to identify the CSFs of PPPs in hydropower sector. The survey was conducted using five-point likert scale self-administrated questionnaire among the 141 respondents sampled out of all the public and private sectors experts and practitioners dealing with PPPs in hydropower sector of Nepal. Through questionnaires, respondents were requested to rate the 21 CSFs (grouped into five) in 1 to 5 point scale being 1 for not important and 5 for most important. The ranking of CSFs has been obtained based on the weighted average mean ranks rated by respondents. Validity of the questionnaire was tested by Cronbach's Alpha which is presented in table 1 . The Alpha computed shows that the collected data are reliable and can be used for analysis.

Table 1: Reliability Statistics

\begin{tabular}{lcc}
\hline \multicolumn{1}{c}{ Variable } & Cronbach's Alpha & N of items \\
\hline Favorable economic condition & 0.745 & 5 \\
Project implementability & 0.836 & 4 \\
Effective procurement & 0.810 & 3 \\
Stable political Environment & 0.864 & 3 \\
Social Environment & 0.913 & 3 \\
Government Support (Control) & 0.861 & 3 \\
\hline
\end{tabular}

\section{FINDINGS OF SURVEY}

\section{Respondents' Profile}

The respondents' profile consists of age, academic qualification, involved sector, and work experience. These details of the profile are shown in the table 2. 
10 I PYC Nepal Journal of Management, August 2017, Vol. X, No. 1

Table 2: Demographic Profile of Respondents ( $\mathrm{N}=141)$

\begin{tabular}{|c|c|c|c|c|c|}
\hline Demographics & Respondents & $\%$ & Demographics & Respondents & $\%$ \\
\hline \multicolumn{3}{|c|}{ Involved Sector: } & \multicolumn{3}{|c|}{ Academic Qualification: } \\
\hline Public Sector & 66 & 47 & Up to Bachelor degree & 26 & 18 \\
\hline Private Sector & 75 & 53 & Masters degree & 82 & 58 \\
\hline Total & 141 & 100 & M. Phil. or PhD & 33 & 23 \\
\hline \multicolumn{3}{|c|}{ Age: } & Total & 141 & 100 \\
\hline Bellow 29 years & 6 & 4 & \multicolumn{3}{|c|}{ Work Experience: } \\
\hline 30 to 39 years & 30 & 21 & 1 to 5 years & 33 & 23 \\
\hline 40 to 44 years & 51 & 36 & 6 to 10 years & 55 & 39 \\
\hline Above 45 years & 54 & 38 & More than 10 years & 53 & 38 \\
\hline Total & 141 & 100 & Total & 141 & 100 \\
\hline
\end{tabular}

Table 2 shows that out of the 141 respondents, $47 \%$ worked for public sectors and remaining $53 \%$ worked for private sectors. Majority of respondents $(58 \%)$ has qualification of Masters Degree. Of the total respondents, the $36 \%$ are age group of 40 to 44 years, and $38 \%$ are age group of above 45 years. Similarly, the 35\% worked for 6 to 10 years and $38 \%$ of respondents worked for more than 10 years in hydropower sector.

\section{Relative Importance of Favorable Economic Condition}

Responses on relative importance of 'Favorable Economic Conditions' have been presented in table 3.

Table 3: Relative Importance of Favorable Economic Condition

\begin{tabular}{|c|c|c|c|c|c|c|}
\hline \multirow{2}{*}{ Favorable Economic Condition } & \multicolumn{2}{|c|}{ Public sector } & \multicolumn{2}{|c|}{ Private sector } & \multicolumn{2}{|c|}{ Overall } \\
\hline & Mean & Rank & Mean & Rank & Mean & Rank \\
\hline Favorable legal framework & 4.53 & 1 & 4.13 & 2 & 4.30 & 2 \\
\hline Stable macro-economic condition & 4.20 & 6 & 4.04 & 6 & 4.11 & 5 \\
\hline Available financial market & 3.80 & 12 & 4.06 & 4 & 3.95 & 7 \\
\hline Appropriate risk allocation and risk sharing & 4.24 & 5 & 3.74 & 12 & 3.95 & 8 \\
\hline Multi-benefit objectives & 4.08 & 7 & 3.60 & 15 & 3.80 & 12 \\
\hline
\end{tabular}

The public sector ranked 'favorable legal framework' as an important success sub factor in the top (4.53 mean), 'macro-economic condition' in the 6th rank (4.2 mean), 'available financial market' in the 12th rank (3.8 mean), 'appropriate risk allocation and sharing' in the 5th rank (4.24 mean), and 'multi- benefit objectives' in the 7th rank (4.08 mean).

The private sector kept 'favorable legal framework' as an important success sub factor in 2nd rank (4.13 mean), 'stable macro-economic condition' in the 6th rank (4.04 mean), 'available financial market' in the 4th rank (4.06 mean), 'appropriate risk allocation and sharing' in the 12th rank (3.74 mean), and 'multi- benefit objectives' in the 15th rank (3.6 mean).

Overall responds kept 'favorable legal framework' in the 2nd rank (4.3 mean), 'stable macro-economic condition' in the 5th rank (4.11 mean), 'available financial market' in 
the 7th rank (3.95 mean), 'appropriate risk allocation and sharing' in the 8th rank (3.95 mean), and 'multi- benefit objectives' in the 12th rank (3.8 mean).

\section{Relative Importance of Project Implementability}

The findings of project implementability as major CSFs have been presented in table 4.

Table 4: Relative Importance of Project Implementablility

\begin{tabular}{|c|c|c|c|c|c|c|}
\hline \multirow{2}{*}{ Implementability Project } & \multicolumn{2}{|c|}{ Public sector } & \multicolumn{2}{|c|}{ Private sector } & \multicolumn{2}{|c|}{ Overall } \\
\hline & Mean & Rank & Mean & Rank & Mean & Rank \\
\hline Project technical feasibility & 4.31 & 3 & 4.43 & 1 & 4.38 & 1 \\
\hline Thorough and realistic assessment of the cost and benefits & 3.92 & 10 & 3.87 & 8 & 3.89 & 9 \\
\hline Commitment and responsibility of public and Private sector & 4.06 & 8 & 3.73 & 13 & 3.87 & 10 \\
\hline Shared authority between public and Private sector & 3.55 & 15 & 3.7 & 14 & 3.64 & 13 \\
\hline
\end{tabular}

Table 4 shows that the public sector responds that 'project technical feasibility' as an important success sub-factor with 3rd rank (4.31 mean), 'thorough and realistic assessment of the cost and benefit' is ranked 10th (3.92 mean), 'commitment and responsibility of public and private sector' is ranked 8th (4.06 mean), and 'shares authority between public and private sector' ranked 15th (3.55 mean).

The private sector responds 'project technical feasibility' as an important success sub factor with top most rank (4.43 mean), 'thorough and realistic assessment of the cost and benefit' is ranked 8th (3.87 mean), 'commitment and responsibility of public and private sector' is ranked 13th (3.73 mean), and 'shares authority between public and private sector' is ranked 14 th (3.7 mean).

Both sectors together responds that 'project technical feasibility' as an important success sub factor with top most rank (4.38 mean); 'thorough and realistic assessment of the cost and benefit' is ranked 9th (3.89 mean), 'commitment and responsibility of public and private sector' is ranked 10th (3.87 mean), and 'shares authority between public and private sector' is ranked 13th (3.64 mean).

\section{Relative Importance of Effective Procurement}

Respondents' opinion on relative importance of effective procurement as a major critical sub-factor has been presented in table 5 .

Table 5: Relative Importance of Effective Procurement

\begin{tabular}{|c|c|c|c|c|c|c|}
\hline \multirow{2}{*}{ Effective Procurement } & \multicolumn{2}{|c|}{ Public sector } & \multicolumn{2}{|c|}{ Private sector } & \multicolumn{2}{|c|}{ Overall } \\
\hline & Mean & Rank & Mean & Rank & Mean & Rank \\
\hline Transparency procurement process & 4.45 & 2 & 4 & 7 & 4.19 & 4 \\
\hline Well organized and committed public agency & 3.63 & 14 & 3.6 & 16 & 3.61 & 14 \\
\hline Competitive procurement process & 3.69 & 13 & 3.53 & 18 & 3.6 & 15 \\
\hline
\end{tabular}


Table 5 shows that the public sector kept 'transparency procurement process' as an important success sub-factor in the 2 nd rank (4.45 mean), 'well organized and committed public agency' in the 14th rank (3.63 mean), and 'competitive procurement process' in 13th rank (3.69 mean).

Similarly, the private sector responds that 'transparency procurement process' is ranked 7 th (4.0 mean), 'well organized and committed public agency' is ranked 16th (3.6 mean), and 'competitive procurement process' is ranked 18th (3.53 mean).

Both sectors responds that 'transparency procurement process' as an important success sub-factor with 4th rank (4.19 mean), 'well organized and committed public agency' is ranked 14th (4.61 mean), and 'competitive procurement process' is ranked 15th (3.6 mean).

\section{Relative Importance of Political Environment}

Responses on relative importance of 'Political Environment Factors' has been presented in table 6.

Table 6: Relative Importance of Political Environment

\begin{tabular}{|c|c|c|c|c|c|c|}
\hline \multirow{2}{*}{ Political Environment } & \multicolumn{2}{|c|}{ Public sector } & \multicolumn{2}{|c|}{ Private sector } & \multicolumn{2}{|c|}{ Overall } \\
\hline & Mean & Rank & Mean & Rank & Mean & Rank \\
\hline Good governance & 4.31 & 4 & 4.11 & 3 & 4.2 & 3 \\
\hline Political environment for PPP's policy making & 3.98 & 9 & 4.06 & 5 & 4.02 & 6 \\
\hline Political parties positive outlook towards the PPPs & 3.9 & 11 & 3.8 & 10 & 3.84 & 11 \\
\hline
\end{tabular}

In the response of public sector 'good governance' is ranked 4th (4.31 mean), 'political environment for PPPs policy making' is ranked 9th (3.98 mean), and 'political parties positive outlook towards the PPPs' is ranked 11th (3.9 mean).

The private sector responds that 'good governance' is ranked 3rd (4.11 mean), 'political environment' for PPPs policy making is ranked 15th (4.06 mean), and 'political parties' positive outlook towards the PPPs is ranked 10th (3.8 mean).

Overall responses kept 'good governance' in 3rd rank (4.2 mean), 'political environment for PPPs policy making' 6th rank (4.02 mean), and 'political parties positive outlook towards the PPPs' 11th rank (3.84 mean).

\section{Relative Importance of Social Environment}

Opinion on relative importance of 'Social Environment' has been presented in table 7.

As presented in table 7, the public sector responds that 'social support' as an important success sub factor is ranked 18th (3.16 mean), 'strong and good private consortium' ranked 16th (3.39 mean), and 'employment opportunities' to the local is ranked 19 th (2.96 mean).

The private sector responds that 'social support' is ranked 11th (3.76 mean), 'strong and good private consortium' is ranked 17th (3.59 mean), and 'employment opportunities 
to the locals' is ranked 19 th (3.4 mean).

Table 7: Relative Importance of Social Environment

\begin{tabular}{|c|c|c|c|c|c|c|}
\hline \multirow{2}{*}{ Social Environment } & \multicolumn{2}{|c|}{ Public sector } & \multicolumn{2}{|c|}{ Private sector } & \multicolumn{2}{|c|}{ Overall } \\
\hline & Mean & Rank & Mean & Rank & Mean & Rank \\
\hline Social support & 3.16 & 18 & 3.76 & 11 & 3.5 & 17 \\
\hline Strong and good private consortium & 3.39 & 16 & 3.59 & 17 & 3.5 & 18 \\
\hline Employment opportunities to the locals & 2.96 & 19 & 3.4 & 19 & 3.21 & 19 \\
\hline
\end{tabular}

In overall, 'social support' is ranked 17th (3.5 mean), 'strong and good private consortium' is ranked with 18th (3.5 mean), and 'employment opportunities to the locals' is ranked 19th (3.21 mean).

Relative Importance of Government Support

Opinion on relative importance of 'Government Support' has been presented in table 8.

Table 8: Relative Importance of Government Support

\begin{tabular}{|c|c|c|c|c|c|c|}
\hline \multirow{2}{*}{ Government Support } & \multicolumn{2}{|c|}{ Public sector } & \multicolumn{2}{|c|}{ Private sector } & \multicolumn{2}{|c|}{ Overall } \\
\hline & Mean & Rank & Mean & Rank & Mean & Rank \\
\hline Government involvement by providing guarantee & 3.18 & 17 & 3.86 & 9 & 3.57 & 16 \\
\hline Government support by providing technical expert & 2.67 & 20 & 3 & 20 & 2.86 & 20 \\
\hline Government support providing management team & 1.94 & 21 & 2.63 & 21 & 2.34 & 21 \\
\hline
\end{tabular}

It is revealed that the public sector ranked 'government involvement by providing guarantee' in the 7 th (3.18 mean), 'government support by providing technical expert' in the 20th (2.67 mean), and 'government support by providing a management team' in 21st (1.94 mean).

The private sector responds that 'government involvement by providing guarantee' is ranked 9th (3.86 mean), 'government support by providing technical expert' is ranked 20th (3.0 mean), 'government support by providing a management team' is ranked $21 \mathrm{st}$ (2.63 mean),

Overall response is that 'government involvement by providing guarantee' is ranked 16th (3.57 mean), 'government support by providing technical expert' is ranked 20th ( 2.86 mean), and 'government support by providing a management team' is ranked $21 \mathrm{st}$ (2.34 mean).

Overall Respondents' Perception Concerning the Importance of CSFS

Based on the overall respondents' results, the top five most CSFs, in descending order of importance have been presented in table 9: 